\title{
Má oclusão de Classe I de Angle, com ausência congênita e impacção de dentes permanentes*
}

\author{
Eduardo Silveira Ferreira**
}

\section{Resumo}

Este artigo relata o tratamento ortodôntico de um paciente com 14 anos e 6 meses de idade, portador de má oclusão de Classe I de Angle, que apresentava ectopia e impacção do dente 45 e ausência congênita do dente 35 . O caso foi tratado com extração do dente 45 e fechamento dos espaços inferiores. Documentações inicial, final e pós-tratamento serão apresentadas e discutidas. Esse caso foi apresentado à Diretoria do Board Brasileiro de Ortodontia e Ortopedia Facial (BBO), representando a categoria 7, livre escolha, como parte dos requisitos para a obtenção do título de Diplomado pelo BBO.

Palavras-chave: Ausência congênita. Má oclusão de Classe I de Angle. Ortodontia corretiva. Impacção dentária.

\section{HISTÓRIA E ETIOLOGIA}

O paciente se apresentou para consulta inicial aos 14 anos e 6 meses de idade, com bom estado geral de saúde, salientando que possuía rinite alérgica e respiração nasobucal. Não relatava histórico de doenças graves ou traumatismos. Apresentavase na curva descendente do crescimento puberal e sua história odontológica incluía higiene bucal deficiente, com presença de gengivite marginal. Sua queixa principal estava relacionada aos espaços edêntulos inferiores, sendo que o tratamento ortodôntico foi recomendado pelo dentista clínico geral. O paciente não havia realizado qualquer intervenção ortodôntica até aquele momento.

\section{DIAGNÓSTICO}

Apresentava padrão esquelético de Classe I, com ANB igual a $1^{\circ}\left(\mathrm{SNA}=81^{\circ}\right.$ e $\left.\mathrm{SNB}=80^{\circ}\right)$, e ângulos do plano mandibular FMA e Eixo Y aumentados em relação às medidas das análises de Steiner e Downs $\left(\mathrm{FMA}=31^{\circ}\right.$ e Eixo $\left.\mathrm{Y}=64^{\circ}\right)$. Essas informações podem ser visualizadas na figura 4 e na tabela 1.

Quanto ao aspecto dentário, como pode ser observado nas figuras 1 e 2 , era portador de uma má oclusão de Classe I de Angle, com problemas localizados (espaços) na região dos segundos pré-molares inferiores, desvio da linha média inferior de $1 \mathrm{~mm}$ à esquerda, apinhamento anteroinferior de $1 \mathrm{~mm}$, sobressaliência de $2 \mathrm{~mm}$, sobremordida de $3 \mathrm{~mm}$ e giroversão nos dentes 15, 25, 22, 23 e 31 .

$\mathrm{Na}$ avaliação facial, apresentava ligeira protrusão labial, com lábio inferior à frente do superior $(\mathrm{LS}=1 \mathrm{~mm}$ e $\mathrm{LI}=3,5 \mathrm{~mm}$ ). Apresentava selamento labial passivo, terço inferior levemente aumentado e não era portador de assimetrias evidentes

* Relato de caso clínico, categoria 7, livre escolha, aprovado pelo Board Brasileiro de Ortodontia e Ortopedia Facial (BBO).

** Mestre e doutor em Ortodontia pela UFRJ. Professor adjunto de Ortodontia da UFRGS. Diplomado pelo Board Brasileiro de Ortodontia e Ortopedia Facial. 

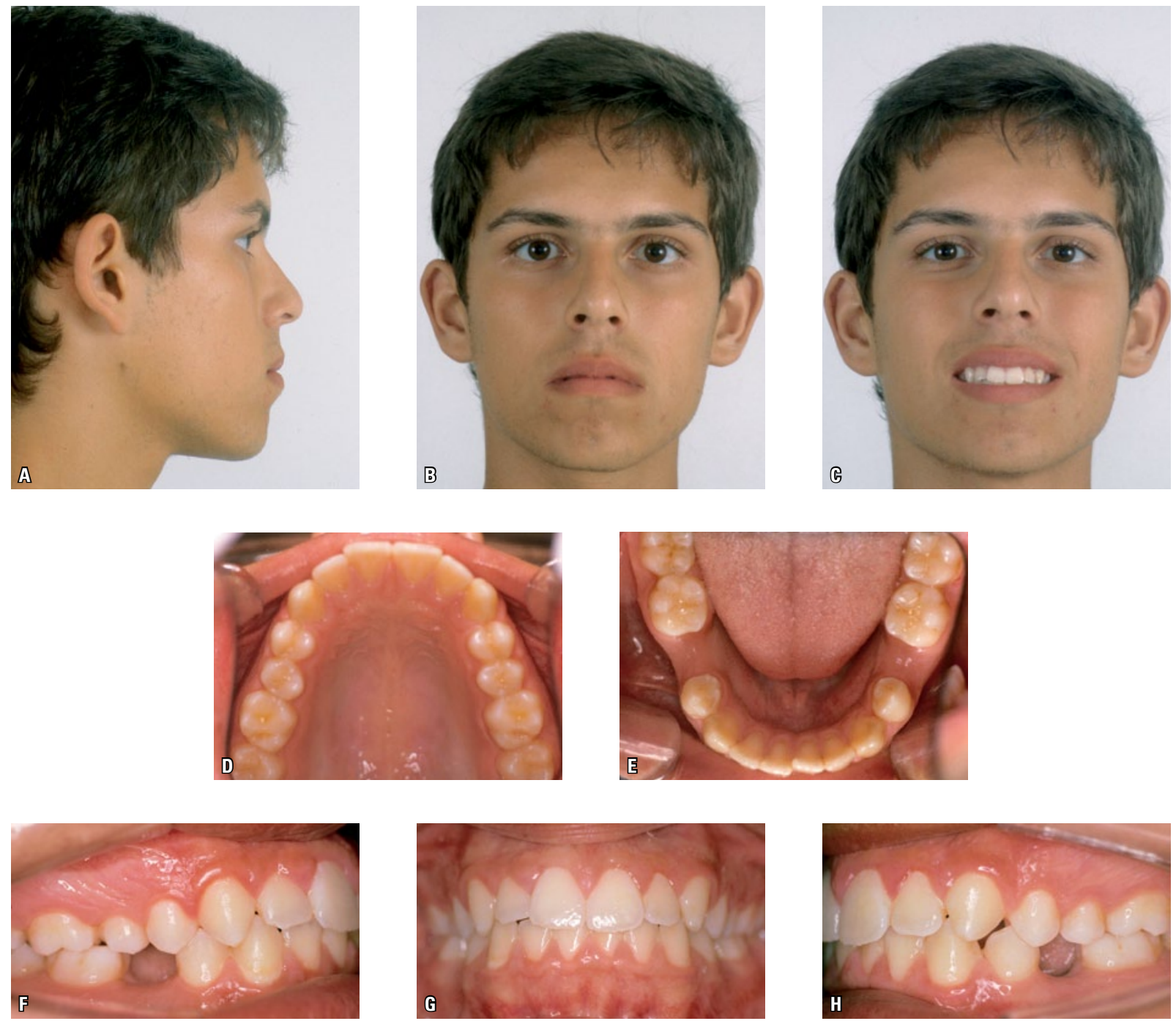

FIGURA 1 - Fotografias faciais e intrabucais iniciais.

nem desvio funcional da mandíbula (Fig. 1).

$\mathrm{Na}$ avaliação radiográfica, foi possivel constatar a ausência dos dentes 35 e 45 e a reabsorção das raízes do dente 46 (Fig. 4, 5). Radiografia panorâmica prévia indicava a impacção prolongada dos dentes 75 e 85 , ectopia com lesão cística do dente 45 , posteriormente diagnosticada como fibroameloblastoma, raízes dos dentes superiores com inclinações axiais incorretas e presença dos terceiros molares (Fig. 3). A radiografia de punho e mão demonstrou os estágios avançados de calcificação das falanges e ossos do punho e a presença do osso sesamoide (Fig. 6). Na radiografia cefalométrica de perfil e no traçado cefalométrico (Fig. 7), observou-se um padrão equilibrado do crescimento facial, vias aéreas superiores desobstruídas, incisivos com inclinação para vestibular e perfil facial reto. Os valores cefalométricos estão apresentados na tabela 1 .

\section{OBJETIVOS DO TRATAMENTO}

Na maxila e na mandíbula, buscou-se manter o posicionamento vertical, transverso e anteroposterior. No arco dentário superior, a proposta foi 

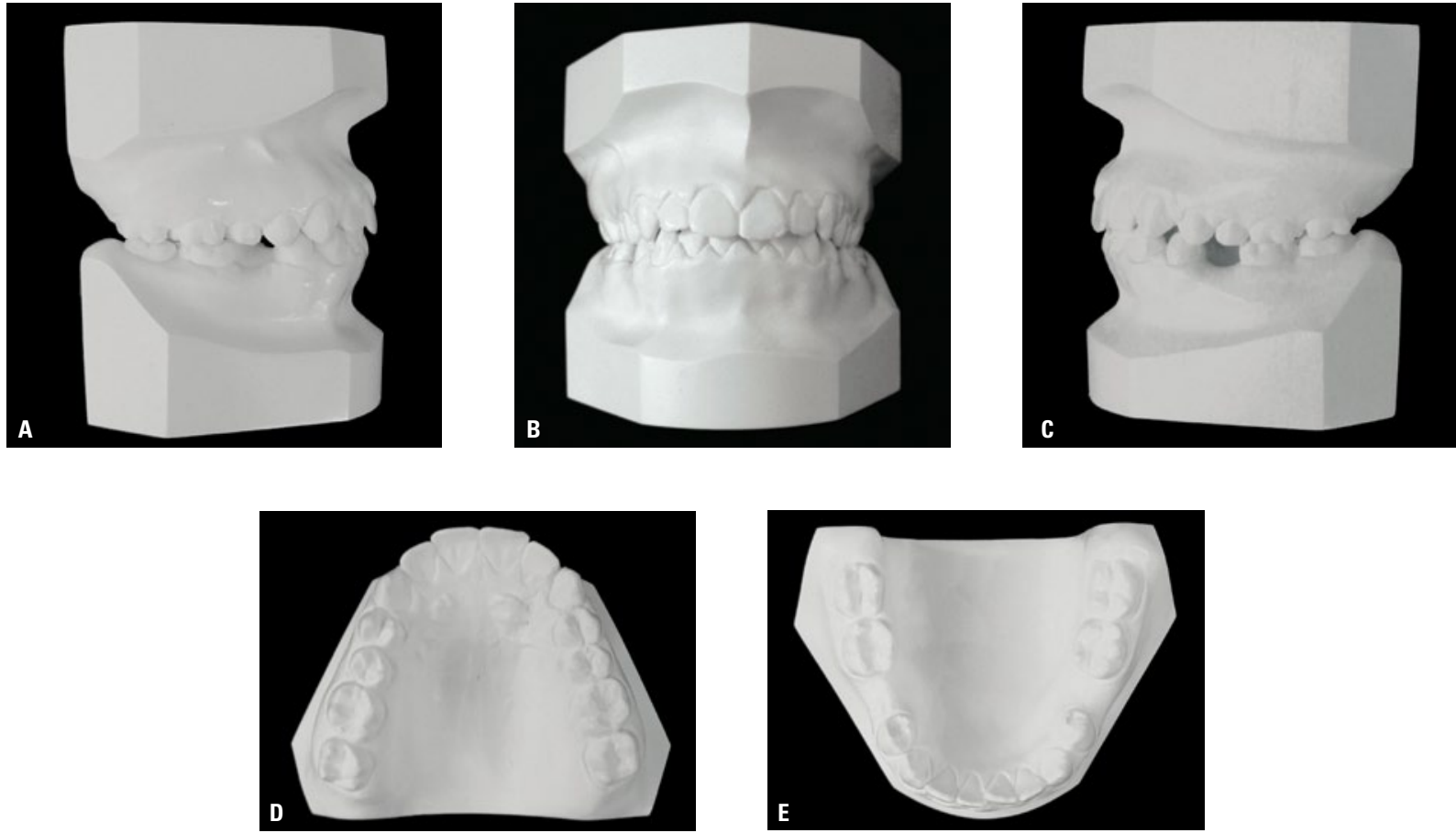

FIGURA 2 - Modelos iniciais.

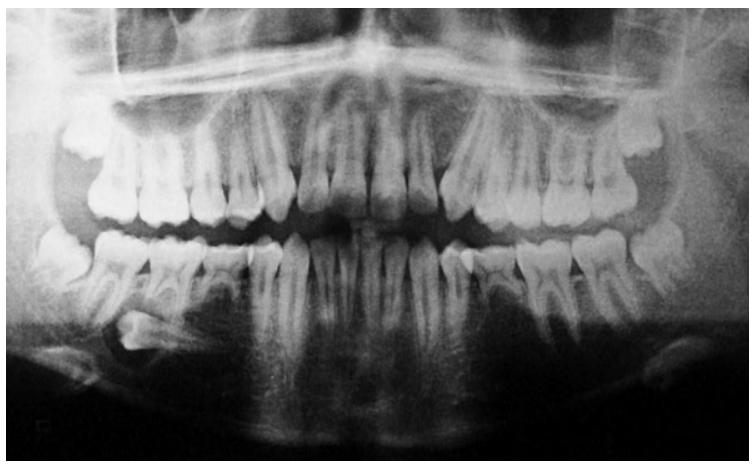

FIGURA 3 - Radiografia panorâmica prévia à consulta inicial.

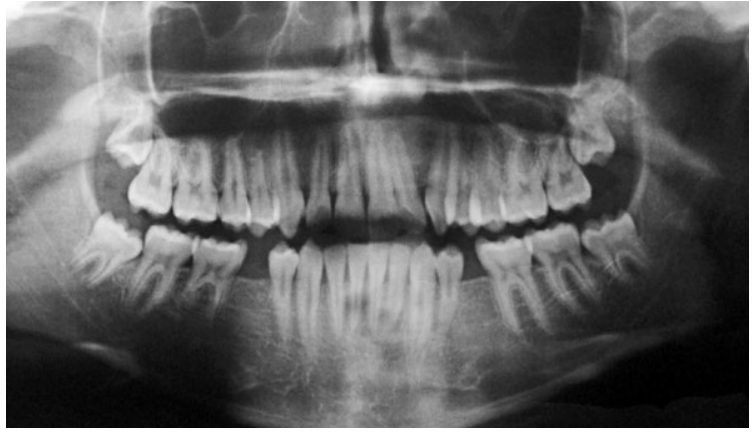

FIGURA 4 - Radiografia panorâmica inicial.

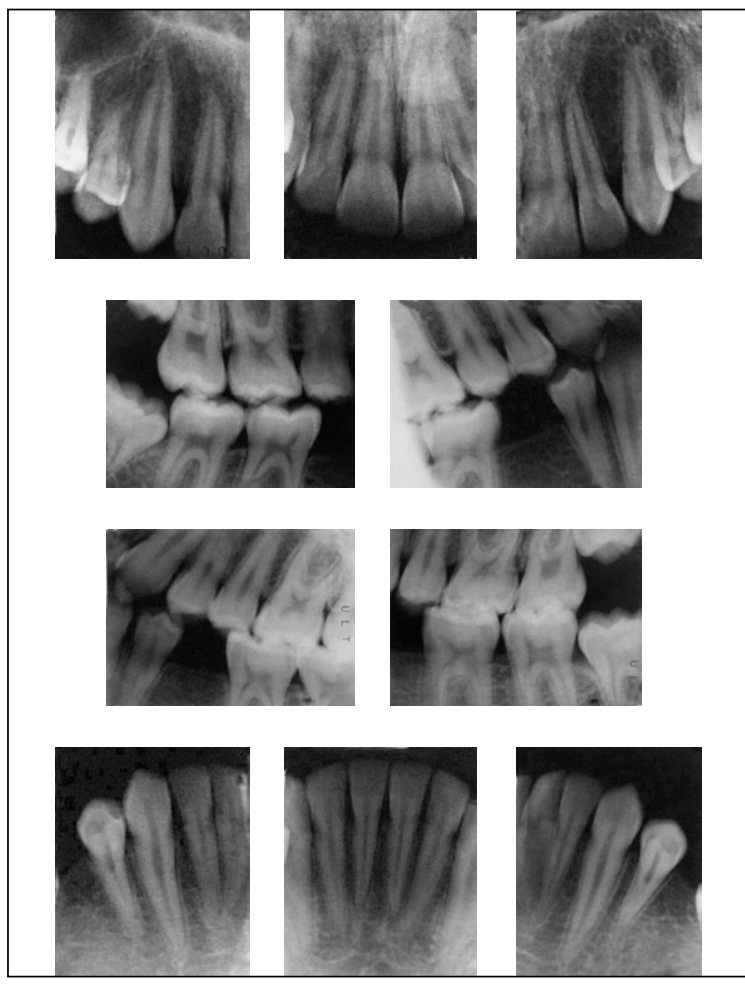

FIGURA 5 - Radiografias periapicais dos dentes anteriores superiores e inferiores interproximais dos lados direito e esquerdo iniciais. 


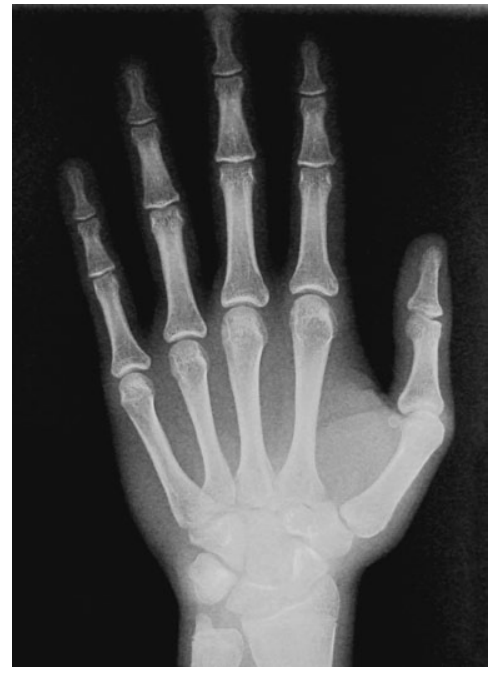

FIGURA 6 - Radiografia de mão e punho inicial.
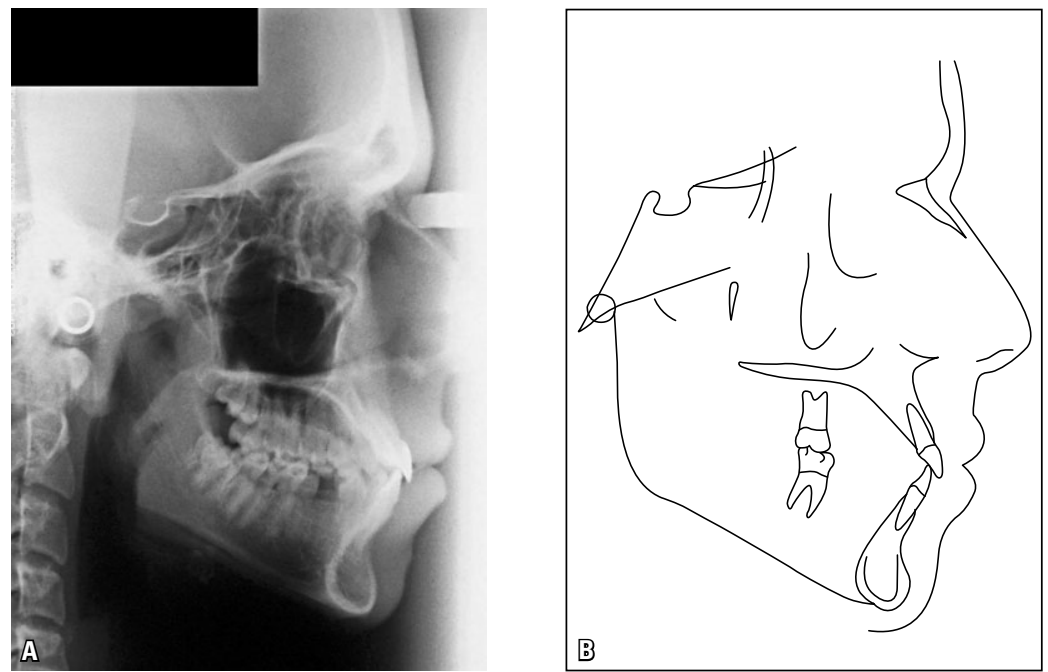

FIGURA 7 - Radiografia cefalométrica de perfil (A) e traçado cefalométrico (B) iniciais. de alinhamento, nivelamento e estabilização, para sua posterior utilização como unidade de ancoragem durante a aplicação da mecânica de elástico com orientação de classe $\mathrm{II}^{10}$. O objetivo específico para a dentição inferior foi de movimentação para mesial dos molares, nivelamento da curva de Spee, mantendo a distância entre os caninos inferiores, e, também, melhora da sobremordida e da sobressaliência. Dessa forma, ao final do tratamento, a relação entre os molares seria de Classe III e, entre os caninos, de Classe I de Angle $^{3}$. O tratamento ortodôntico visando à manutenção dos espaços para recomposição com implantes e próteses dos dentes 45 e 35 foi descartado pelo paciente, que não desejava elementos artificiais na cavidade bucal. De comum acordo, portanto, foi executado o planejamento de fechamento completo dos espaços presentes nessa região.

\section{PLANO DE TRATAMENTO}

Para atingir os objetivos propostos, o paciente foi informado sobre o plano de tratamento elaborado, que consistia de montagem do aparelho ortodôntico fixo superior e inferior, sistema Edgewise, standard, slot 0,022" x 0,028" e arcos redondos de aço inoxidável 0,014", 0,016", 0,018” e 0,020", para alinhamento e nivelamento. A partir do arco 0,020", seriam utilizados elásticos em cadeia, para movimentação para mesial dos molares inferiores, mantendo os dentes anteriores amarrados conjuntamente (tie together). Posteriormente, este movimento continuaria a ser realizado com arcos 0,018 " x 0,025", quando, se necessário, seriam instalados elásticos com orientação de classe II (magnitude de força 180g) em ambos os lados. Para a finalização, seriam utilizados arcos 0,019 " x 0,026", superior e inferior, com dobras individualizadas conforme a necessidade. Após o término do tratamento ativo, seria utilizada uma placa superior removível (wraparound), confeccionada com fio de aço inoxidável 0,032" e, no arco dentário inferior, uma barra lingual colada nos dentes 43 e 33, confeccionada com fio redondo trançado 0,032". Não estava descartada a possibilidade de extração dos terceiros molares superiores e, também, da colagem de segmentos de fio de aço inoxidável na face vestibular dos dentes 46 a 44 e 36 a 34 . O paciente foi informado, por escrito, dos cuidados necessários com seu aparelho ortodôntico, bem como com sua higiene bucal ${ }^{4}$. 


\section{PROGRESSO DO TRATAMENTO}

Foram confeccionados anéis ortodônticos com acessórios soldados nos molares superiores e inferiores e, nos demais dentes, foram colados braquetes, sistema Edgewise, standard, com slot 0,022" x 0,028 ".

Para alinhamento e nivelamento, foram instalados, sequencialmente, nos arcos dentários superior e inferior, arcos de aço inoxidável 0,014" a 0,020". No arco dentário inferior, a partir do arco 0,020", foi realizada uma amarração conjunta (tie together) do primeiro pré-molar do lado esquerdo ao do lado direito, e os molares foram movimentados mesialmente com o auxílio de elásticos em cadeia. Essa mecânica foi mantida quando, na sequência, o arco inferior foi substituído por um arco de aço inoxidável 0,018 " x 0,025". Para auxiliar a perda de ancoragem no arco inferior, foi instituída mecânica de elástico de Classe II (180g), em ambos os lados.

Após o fechamento dos espaços dos molares inferiores, o caso foi finalizado com $\operatorname{arcos} 0,019$ " $\mathrm{x}$ 0,026 ", superior e inferior.
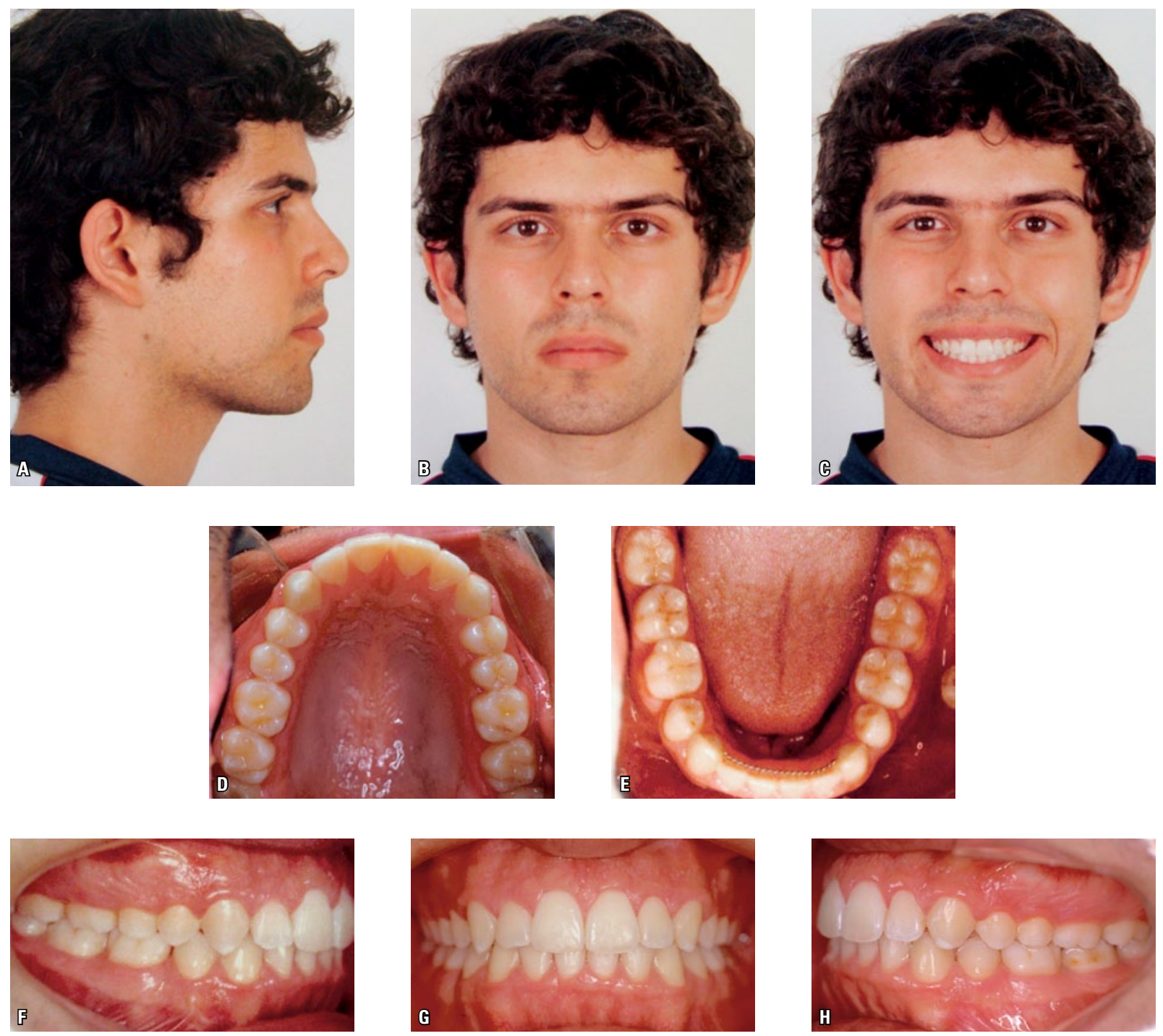

FIGURA 8 - Fotografias faciais e intrabucais finais. 

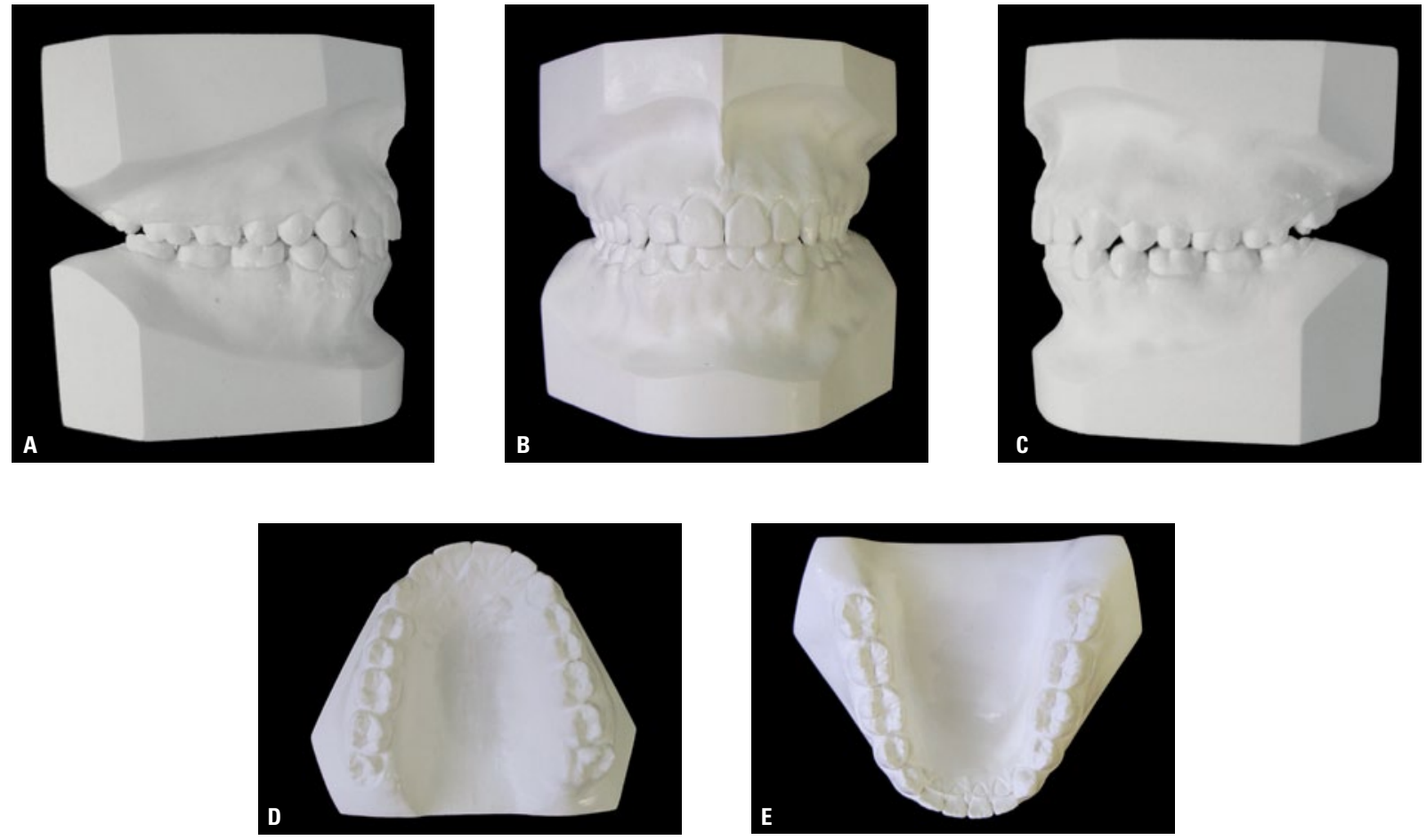

FIGURA 9 - Modelos finais.

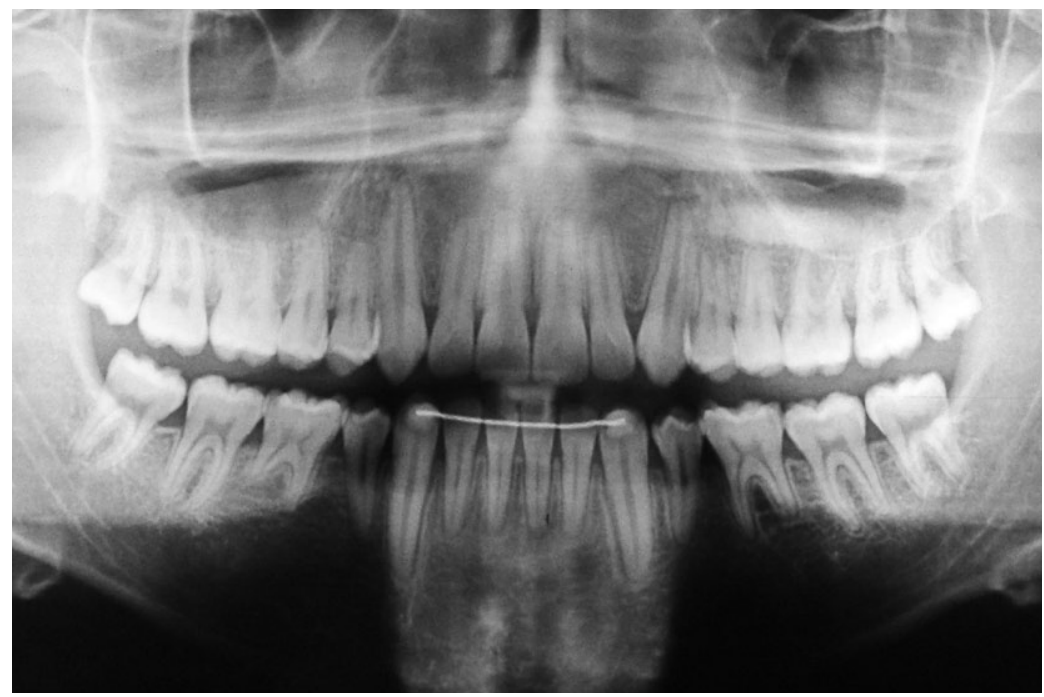

FIGURA 10 - Radiografia panorâmica final.

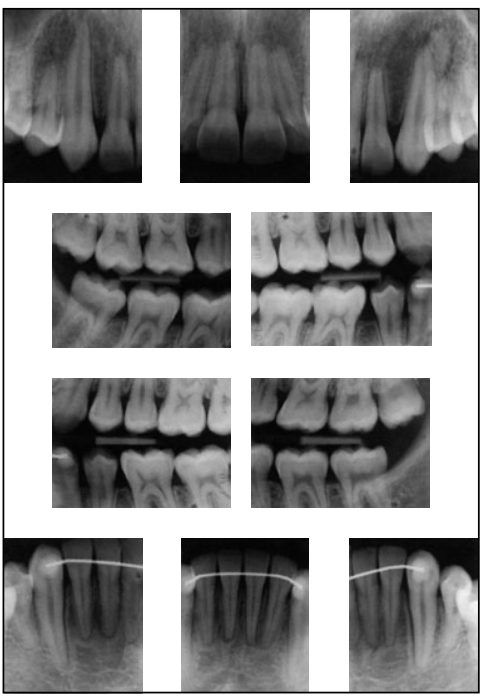

FIGURA 11 - Radiografias periapicais dos dentes anteriores superiores e inferiores e interproximais dos lados direito e esquerdo finais. 
Com a verificação de que todos os objetivos pretendidos foram alcançados, o aparelho ortodôntico fixo foi removido, iniciando-se, então, a fase de contenção. Foi utilizada uma placa removível superior (wraparound), confeccionada com fio de aço inoxidável 0,032", e uma barra inferior colada nos dentes 33 e 43, confeccionada com fio redondo trançado 0,032". Recomendou-se a utilização da placa superior durante 24 horas por dia, no primeiro ano, e, após esse período, uso noturno por mais um ano. A barra intercaninos inferior foi recomendada para uso por tempo indeterminado.

\section{RESULTADOS DO TRATAMENTO}

Avaliando-se os registros finais do paciente (Fig. 8-12), pode-se verificar que os objetivos propostos foram atingidos ${ }^{1,9}$. Na maxila, foram mantidas as posições das bases ósseas e a dentição superior apresentou leve retração dos incisivos. Os molares inferiores apresentaram movimentação para mesial e diminuição da distância intermolares $(46,5 \mathrm{~mm}$ para $43 \mathrm{~mm})$, enquanto a distância entre os caninos praticamente se manteve (Tab. 2). Os resultados da análise cefalométrica indicam a manutenção do padrão esquelético do paciente,
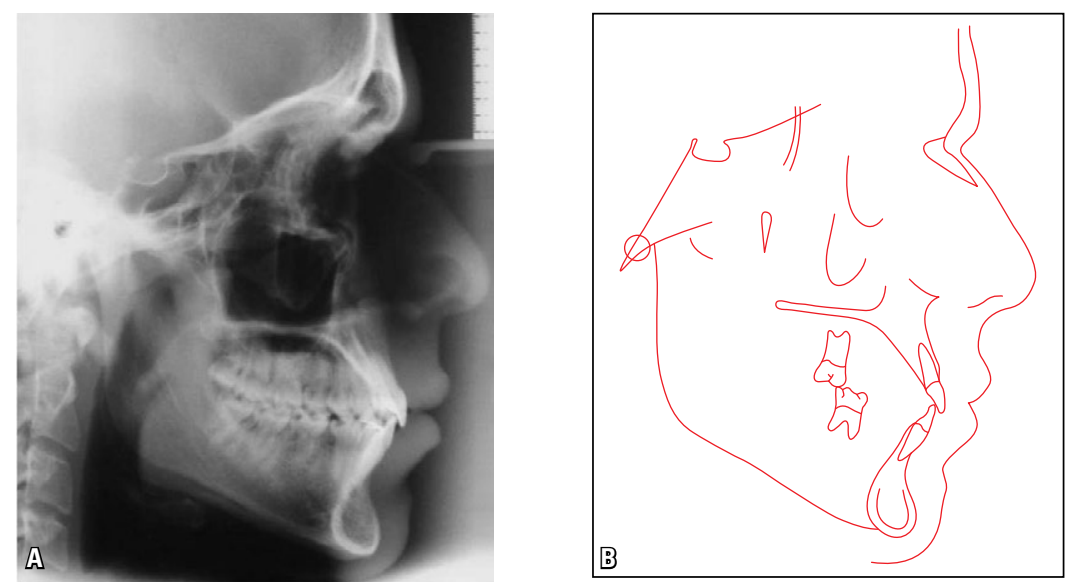

FIGURA 12 - Radiografia cefalométrica de perfil (A) e traçado cefalométrico (B) finais.
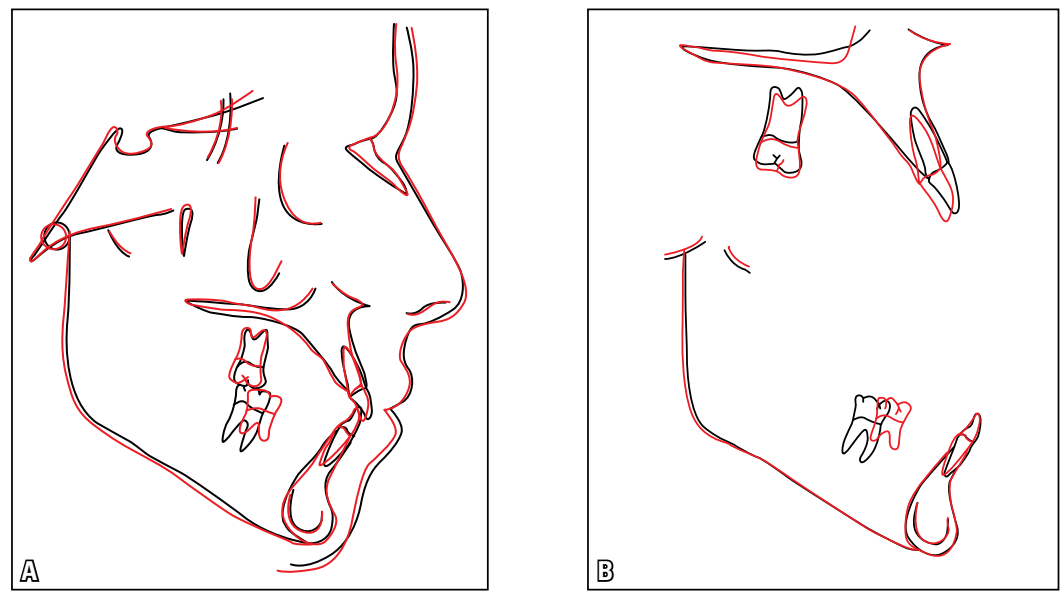

FIGURA 13 - Sobreposições total (A) e parciais (B) dos traçados cefalométricos inicial (preto) e final (vermelho). 
TABELA 1 - Resumo das medidas cefalométricas.

\begin{tabular}{|c|c|c|c|c|c|c|}
\hline & MEDIDAS & NORMAL & $\mathbf{A}$ & B & $\begin{array}{c}\text { DIFERENÇA } \\
\text { A - B }\end{array}$ & C \\
\hline \multirow{8}{*}{ 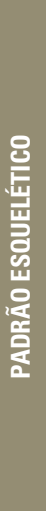 } & SNA (Steiner) & $82^{\circ}$ & $81^{\circ}$ & $81^{\circ}$ & 0 & $80^{\circ}$ \\
\hline & SNB (Steiner) & $80^{\circ}$ & $80^{\circ}$ & $80^{\circ}$ & 0 & $80^{\circ}$ \\
\hline & ANB (Steiner) & $2^{\circ}$ & $1^{0}$ & $1^{\circ}$ & 0 & $0^{\circ}$ \\
\hline & Ângulo de Convexidade (Downs) & $0^{\circ}$ & $-2^{\circ}$ & $0^{\circ}$ & 2 & $-1^{0}$ \\
\hline & Eixo Y (Downs) & $59^{\circ}$ & $64^{\circ}$ & $61^{\circ}$ & 3 & $62^{\circ}$ \\
\hline & Ângulo Facial (Downs) & $87^{\circ}$ & $85^{\circ}$ & $83^{\circ}$ & 2 & $86^{\circ}$ \\
\hline & SN - GoGn (Steiner) & $32^{\circ}$ & $32^{\circ}$ & $30^{\circ}$ & 2 & $31^{\circ}$ \\
\hline & FMA (Tweed) & $25^{\circ}$ & $31^{\circ}$ & $31^{\circ}$ & 0 & $30^{\circ}$ \\
\hline \multirow{7}{*}{ 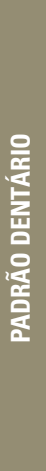 } & IMPA (Tweed) & $90^{\circ}$ & $85^{\circ}$ & $89^{\circ}$ & 4 & $89^{\circ}$ \\
\hline & $\underline{1}$ - NA (graus) (Steiner) & $22^{\circ}$ & $20^{\circ}$ & $22^{\circ}$ & 2 & $21^{\circ}$ \\
\hline & 1 - NA (mm) (Steiner) & $4 \mathrm{~mm}$ & $11 \mathrm{~mm}$ & $8 \mathrm{~mm}$ & 3 & $9 \mathrm{~mm}$ \\
\hline & $\overline{1}-\mathrm{NB}$ (graus) (Steiner) & $25^{\circ}$ & $21^{\circ}$ & $23^{\circ}$ & 2 & $22^{\circ}$ \\
\hline & $T$ - NB (mm) (Steiner) & $4 \mathrm{~mm}$ & $8 \mathrm{~mm}$ & $7 \mathrm{~mm}$ & 1 & $6 \mathrm{~mm}$ \\
\hline & Ângulo Interincisal (Downs) & $130^{\circ}$ & $133^{\circ}$ & $134^{\circ}$ & 1 & $135^{\circ}$ \\
\hline & T-APo (mm) (Ricketts) & $1 \mathrm{~mm}$ & $6 \mathrm{~mm}$ & $4,5 \mathrm{~mm}$ & 1,5 & $5 \mathrm{~mm}$ \\
\hline \multirow{2}{*}{$\begin{array}{l}\text { 램 } \\
\text { 盖 }\end{array}$} & Lábio Superior - Linha S (Steiner) & $0 \mathrm{~mm}$ & $1 \mathrm{~mm}$ & $0 \mathrm{~mm}$ & 1 & $0 \mathrm{~mm}$ \\
\hline & Lábio Inferior - Linha S (Steiner) & $0 \mathrm{~mm}$ & $3,5 \mathrm{~mm}$ & $1 \mathrm{~mm}$ & 2,5 & $0 \mathrm{~mm}$ \\
\hline
\end{tabular}

com leve diminuição nos valores do Eixo Y e do ângulo SN-GoGn. Houve, também, diminuição dos valores lineares e aumento dos valores angulares dos incisivos. No perfil facial, houve recuo de $1 \mathrm{~mm}$, no lábio superior, e de $2,5 \mathrm{~mm}$, no lábio inferior, em relação à linha $\mathrm{S}$ de Steiner (Tab. 1).

$\mathrm{Na}$ análise da radiografia panorâmica (Fig. 10), observa-se bom paralelismo radicular, com exceção da região entre incisivos laterais e caninos superiores, e ausência de lesão na região do fibroameloblastoma (dente 45). Houve, também, arredondamento generalizado nas raízes dos incisivos
TABELA 2 - Medidas das distâncias transversais dos arcos dentários (mm).

\begin{tabular}{lcccc}
\multicolumn{1}{c}{ MEDIDAS } & A & B & A - B & C \\
$\begin{array}{l}\text { Distância } \\
\text { intercaninos inferiores }\end{array}$ & $29,5 \mathrm{~mm}$ & $29 \mathrm{~mm}$ & 0,5 & $30 \mathrm{~mm}$ \\
$\begin{array}{l}\text { Distância } \\
\text { intermolares inferiores }\end{array}$ & $46,5 \mathrm{~mm}$ & $43 \mathrm{~mm}$ & 3,5 & $42 \mathrm{~mm}$ \\
$\begin{array}{l}\text { Distância } \\
\text { intercaninos superiores }\end{array}$ & $37 \mathrm{~mm}$ & $38 \mathrm{~mm}$ & 1 & $38 \mathrm{~mm}$ \\
$\begin{array}{l}\text { Distância } \\
\text { intermolares superiores }\end{array}$ & $54 \mathrm{~mm}$ & $54 \mathrm{~mm}$ & 0 & $55 \mathrm{~mm}$ \\
\hline
\end{tabular}


superiores e perda radicular mais significativa nos dentes 36 e 46 . As demais estruturas se apresentavam dentro da normalidade, incluindo os terceiros molares, que já se encontravam irrompidos.

A oclusão dentária apresentou melhora na intercuspidação entre os molares, mesmo com a relação dos segundos pré-molares superiores com os primeiros molares inferiores e a oclusão dos segundos molares superiores com os terceiros molares inferiores. A estética facial não apresentou alterações expressivas e a linha do sorriso apresentou melhora significativa, com o alinhamento dos dentes anteriores. O tempo total de tratamento foi de 39 meses e a contenção superior foi recomendada para o uso de 24 horas por dia durante um ano e mais 12 meses de uso noturno.

Os exames obtidos após cinco anos do término do tratamento ortodôntico corretivo (Fig. 14 18) mostram a estabilidade das posições obtidas, o fechamento de espaços residuais e o pequeno aumento da sobremordida. Na análise radiográfica, as reabsorções dos dentes 46 e 36 não apresentaram
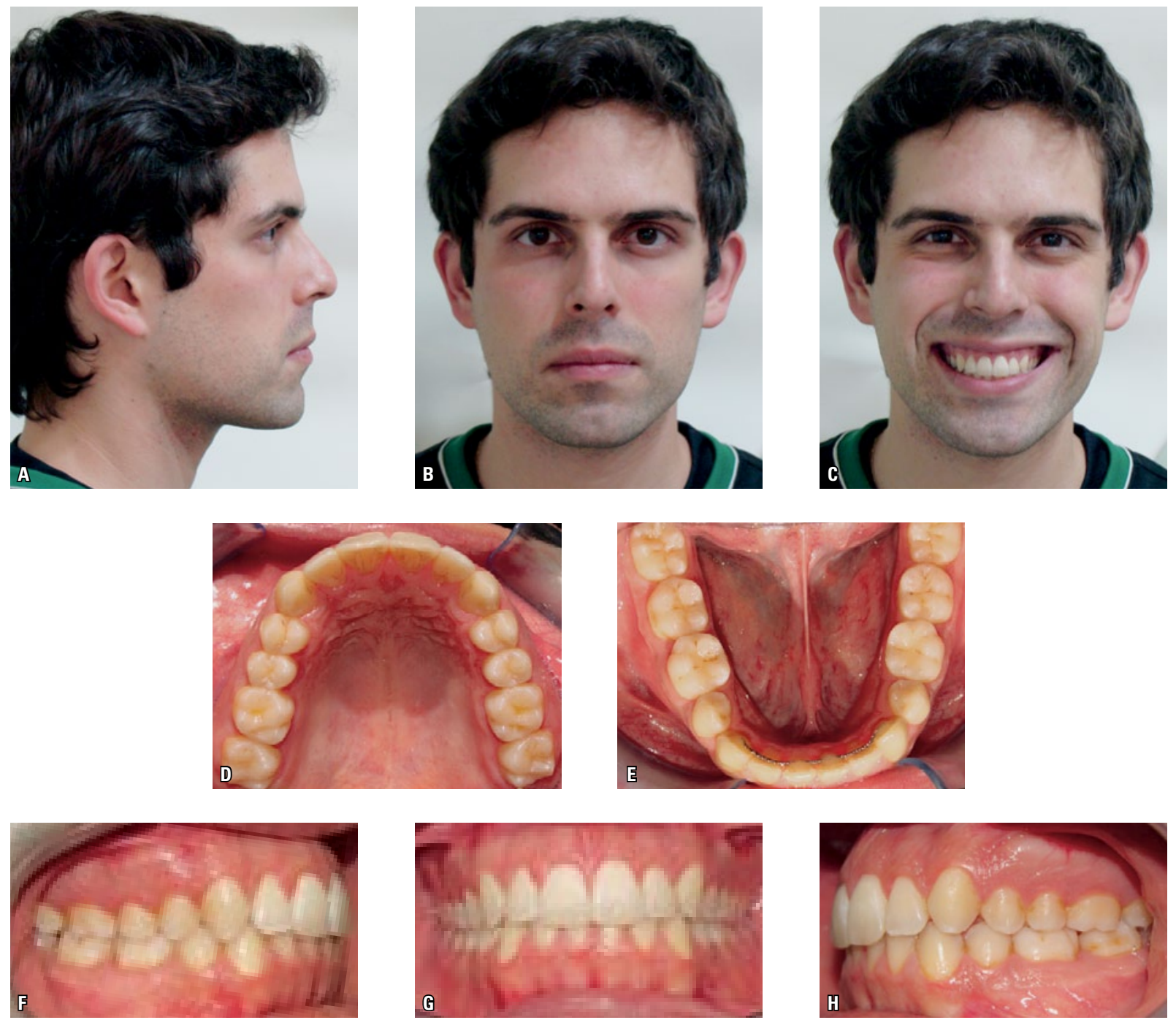

FIGURA 14 - Fotografias faciais e intrabucais de controle cinco anos após o término do tratamento. 

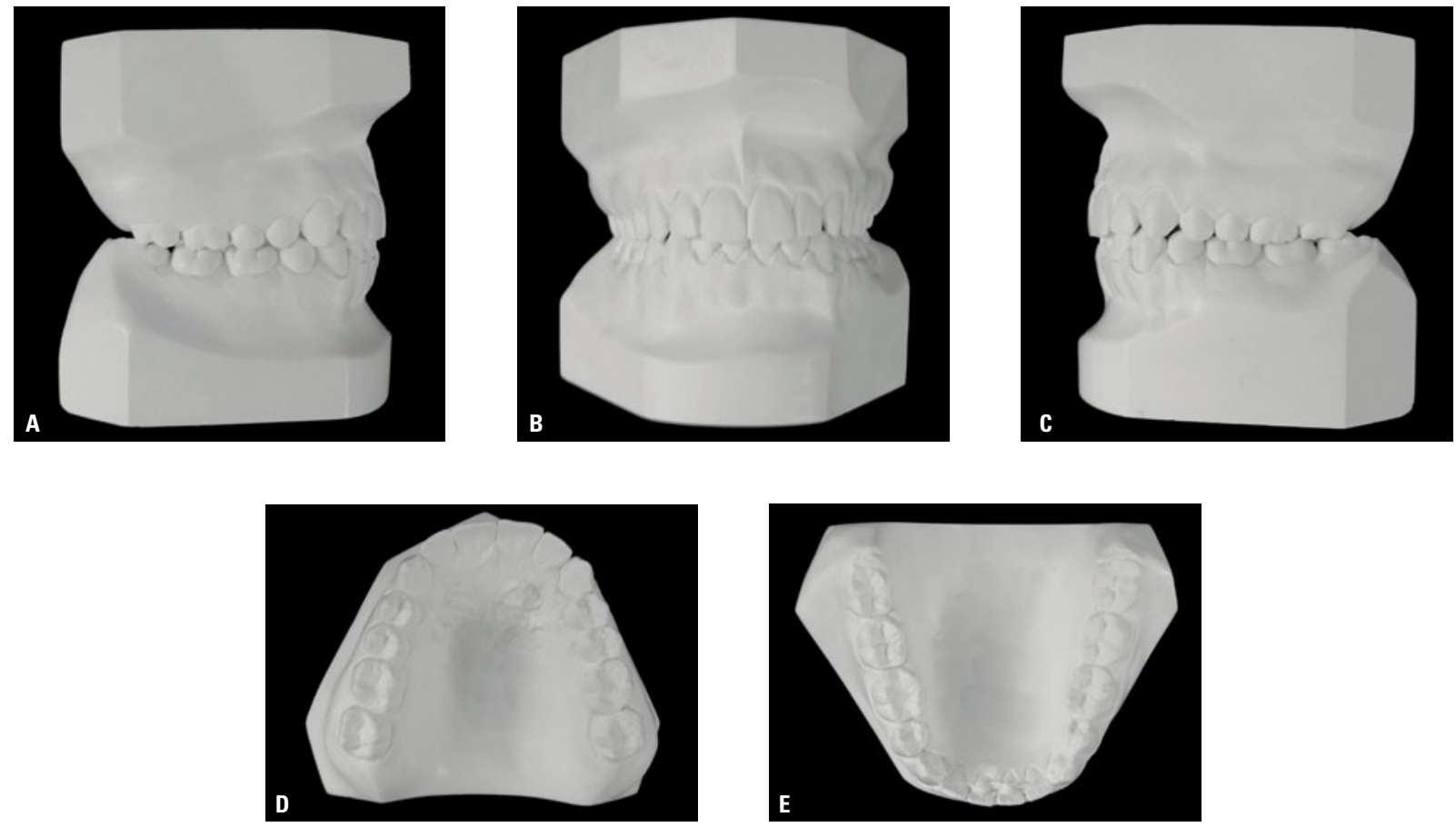

FIGURA 15 - Modelos de controle cinco anos após o término do tratamento.

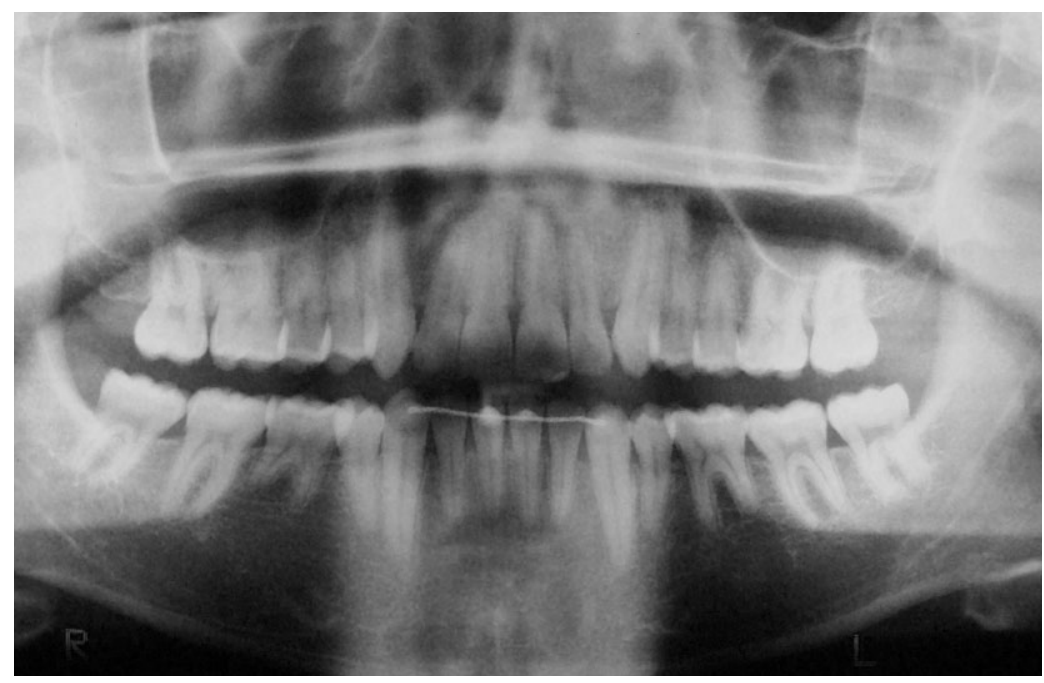

FIGURA 16 - Radiografia panorâmica de controle cinco anos após o término do tratamento. 

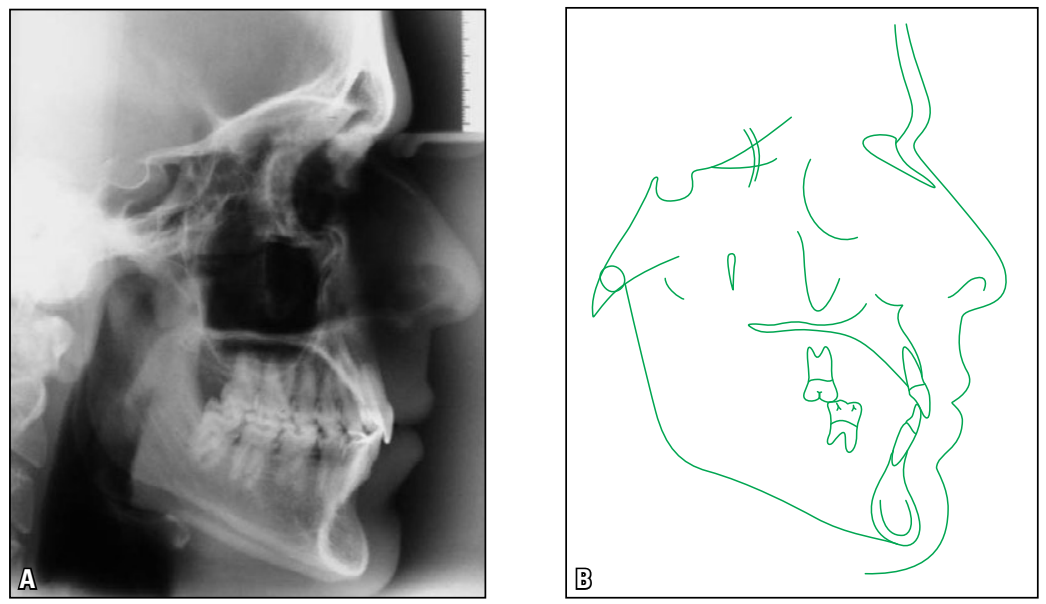

FIGURA 17 - Radiografia cefalométrica de perfil (A) e traçado cefalométrico (B) de controle cinco anos após o término do tratamento.
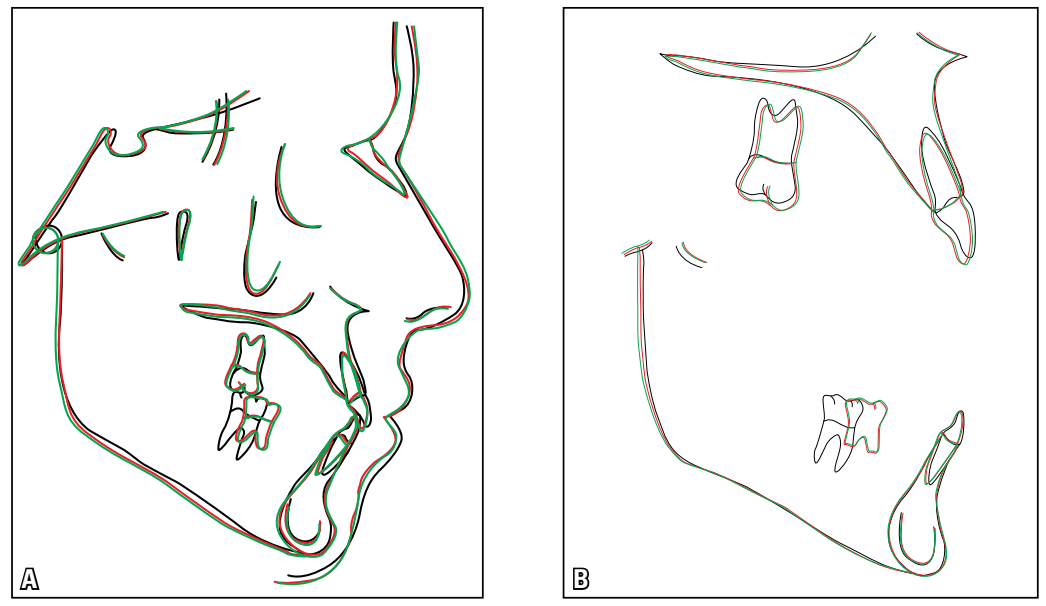

FIGURA 18 - Sobreposições total (A) e parciais (B) dos traçados cefalométricos inicial (preto), final (vermelho) e de controle cinco anos após o término do tratamento (verde).

evolução após o término do tratamento ${ }^{2}$. Os terceiros molares superiores foram extraídos e a área da lesão cística se apresenta com aspecto ósseo normal. Os valores cefalométricos e as distâncias entre os caninos e molares apresentaram pequena variação, como pode ser observado nas tabelas 1 e 2 .

\section{CONSIDERAÇÕES FINAIS}

Os resultados do tratamento foram obtidos com o fechamento dos espaços ocasionados pela ausência congênita do dente 35 e pela necessidade de exodontia do dente 45 . O paciente foi excelente colaborador no uso dos dispositivos ortodônticos, assíduo nas consultas e responsável em seus deveres. Foi informado aos responsáveis a situação difícil em relação à reabsorção das raízes do dente 46 e não foi descartada a necessidade de extração do mesmo, para futura colocação de implante/prótese, devido à pouca inserção radicular provocada pela lesão cística e pela movimentação ortodôntica. Os registros de cinco anos após o término do tratamento demonstram boa 
estabilização dessa situação. Controle radiográfico periapical periódico foi realizado durante o tratamento. O primeiro molar inferior do lado esquerdo (36) também apresentou reabsorção radicular, certamente pela extensa movimentação para mesial, até obter contato com o dente 34 . As sobreposições dos traçados cefalométricos total (da face) e parciais (de maxila e mandibula) demonstram a evolução do padrão facial associado à mecânica ortodôntica descrita no plano de tratamento (Fig. 13, 18). O paciente permanece em controle com o cirurgião bucomaxilofacial, responsável pela remoção da lesão, prévia ao início do tratamento ortodôntico, para diagnosticar qualquer recidiva.

\title{
Angle Class I malocclusion with congenitally absence and impaction of permanent teeth
}

\begin{abstract}
This article reports the orthodontic treatment of a 14 year and 6 months old patient that had a Angle Class I malocclusion with an ectopic position and impaction of the tooth 45 and congenitally absence of tooth 35 . This case was treated with the extraction of the tooth 45 and space closure in the lower arch. Initial, final and post-treatment orthodontic records will be presented and discussed. This case was presented to the Brazilian Board of Orthodontics and Facial Orthopedics (BBO), representing the category 7, free choice, as part of the requirements for achieving the title of BBO diplomate.
\end{abstract}

Keywords: Angle Class I malocclusion. Tooth impaction. Congenitally missing tooth. Corrective Orthodontics.

\section{REFERÊNCIAS}

1. ANDREWS, L. F. The six keys to normal occlusion. Am. J. Orthod., St. Louis, v. 62, no. 3, p. 296-309, Sept. 1972.

2. CONSOlARO, A.; CONSOLARO, M. F. M. O. Controvérsias na Ortodontia \& atlas de Biologia da movimentação dentária. 1. ed. Maringá: Dental Press, 2008.

3. DAWSON, P. E. Avaliação, diagnóstico e tratamento dos problemas oclusais. 2. ed. São Paulo: Artes Médicas, 1993.

4. GRABER, T. M. VANARSDALL, R. L. Ortodontia: princípios e técnicas atuais. 3. ed. Rio Janeiro: Guanabara Koogan, 2002.

5. $\mathrm{KOKICH}, \mathrm{V}$. Early management of congenitally missing teeth. Semin. Orthod., Philadelphia, v. 11, no. 3, p. 146-151, Sept. 2005.
6. LANGLADE, M. Cefalometria ortodôntica. 1 ed. São Paulo: Ed. Santos, 1993.

7. LIMA FILHO, R. M. A.; BOLOGNESE, A. M. Ortodontia: arte e ciência. 1. ed. Maringá: Dental Press, 2008.

8. PROFFIT, W. R.; FIELDS JÚNIOR, H. W. SARVER, D. M. Ortodontia contemporânea. 4. ed. Rio de Janeiro: Elsevier, 2008.

9. STRANG, R. Tratado de Ortodontia. 3. ed. Buenos Aires: Ed. Bibliográfica Argentina, 1957.

10. TWEED, C. H. Clinical Orthodontics. St. Louis: C.V. Mosby, 1966. v. 1.
Endereço para correspondência

Eduardo Silveira Ferreira

Rua Dona Laura, 87 conjunto 301 - bairro Rio Branco

CEP: $91430-091$ - Porto Alegre / RS

E-mail: clinicaeferreira@terra.com.br 